\title{
Pre-graduation Grade Inflation in Medical Training in Turkey: A Longitudinal Study From 2005 to 2020
}

ENGIN KARADAG ( $\nabla$ engin.karadag@hotmail.com )

Akdeniz University

\section{Research Article}

Keywords: Medical training, higher education, pre-graduation medical training, grade inflation.

Posted Date: February 8th, 2021

DOI: https://doi.org/10.21203/rs.3.rs-154615/v1

License: (1) This work is licensed under a Creative Commons Attribution 4.0 International License. Read Full License

Version of Record: A version of this preprint was published at BMC Medical Education on July 22nd, 2021. See the published version at https://doi.org/10.1186/s12909-021-02819-0. 


\section{Abstract}

Background: Grade inflation in higher education institutions, that is the increase in students' grades, has been observed since the 1960s. There are comprehensive proofs that document the allegations, prevalence and severity of grade inflation in higher education especially in American universities for the past 10 years. This study analyzes the change in the ratio of those graduated with a "very good $(>2.99)$ " degree from medical education in Turkey within a 15year-long period, the grade inflation (when all other factors are constant), and factors that affect the course grade.

Methods: The analyses were carried out using the grade point average (GPA) of 9.618 students graduated from the medical faculty of 25 universities in Turkey, and 288.540 student grade for 7.597 courses. The study used the "real" university random effects estimator modeling considering the differences in universities with correlation, ANOVA, t-test and ANCOVA analyses.

Results and Conclusion: The results revealed that there was a marginal increase in grades in medical training before graduation after checking the effects of factors that might affect the graduation grades. The $29 \%$ grade inflation detected is in line with the literature and is one of the highest values that have been reported so far. It was also detected that the ratio of graduates with a "very good (>2.99)" degree was $17 \%$ in 2005 and it increased to $46 \%$ in 2020 .

Additionally, the class size, academic degree of the tutor, grade, content of the course, types of the universities (public \& non-profit private), accreditation of the program, and the age of the faculty are important determinants of course grades. According to these results, it is clear that both the uncontrolled expansion of medical faculties in Turkey and the decrease in quality cause an increase in grades. One of the most important results obtained is that accreditation slows down the grade inflation. Both the course grades following the accreditation process and the inflation in the graduation grades (grade inflation) slowed down significantly in the accredited faculties. This finding is an important example of the necessity of accreditation, which is referred to as the "golden standard" to improve the quality of medical education.

\section{Introduction}

Pre-graduation medical training assessment is a critical part of acquired competencies and improvements. However, the most important compound that is disregarded in the assessments is the graduation and course grades. There is a general opinion in the literature that grading in medical education is standardized insufficiently and is often subjective ${ }^{1}$. In this regard, grade inflation is a process that reduces the real value of grade $A$ to a medium grade ${ }^{2}$. The grade inflation weakens standards; thus, it becomes difficult to compare grades with knowledge and competencies ${ }^{3}$. Inflating the grades increases the tendency to wonder what is the essence of the grade ${ }^{4}$. Lately, there is a growing awareness that grade inflation might cause a greater problem compared to previous years. These thoughts result in a common subject: How the sufficiency of the assessment will be ensured to measure students' progress. How can instructors compare students' results if they are different than previous years? On one hand, if students get higher scores than previous years, can this be the outcome of better homework, a more planned syllabus, and communicating more with students about the requirements of the course? Although grade inflation is not a problem limited to one discipline, the number of studies that answer these questions and are about grade inflation is limited in the relevant literature compared to other disciplines. Therefore, the main focus of this study is to examine the change in the ratio of those graduated with a "very good (> 2.99)" degree from medical education in Turkey, "grade inflation" and factors that affect course grades considering the need for studies on whether this phenomenon exists in reality, and if it is, what are the consequences of it in medical education circle. Data included the Grade Point Average (GPA) of 9.618 graduates of 25 universities in 15 years between 2005 and 2020, and 288.540 student grades for 7.597 courses. The number of studies on "grade inflation in medical education" is quite limited. The methodology of the study was planned as helping the assessment of whether the current worries about "grade inflation" are right.

\section{Background}

Students receive gradings to indicate their academic success ${ }^{5}$. When the grades are inflated, the tendency to question the rationale behind the grading increases ${ }^{4}$. In this respect, "grade inflation" is a common explanation for rising notes in terms of giving higher grades to equivalent work. Although empirical literature on grade inflation in higher education outside the US is inadequate, this case has been widely investigated in the US 6,7. In particular, over the last few decades, note inflation claims in higher education have increased in US universities, along with extensive evidence documenting its prevalence and seriousness. It is known that students spend less time studying in grade-inflated classes. Additionally, students who receive inflated grades in entry-level or prerequisite classes often stated that they felt inadequate in advanced courses and presented the tendency of grade inflation as the reason ${ }^{8}$.

An increase in grade inflation in higher education institutions was noted, i.e., the grades of students began to increase from the 1960s. One of the pioneering studies in literature, a comprehensive survey conducted by Kuh and Hu (1999), argued that grades were higher in the 1990s than in the 1980s, and average grades increased in all higher education institutions. Researchers claimed that this was due to more women attending higher education in the 1990 s than in the 1980s and may not be due to grade inflation. However, recent studies disprove Kuh and Hu's statements. Eiszler (2002) studied the 20-year data at a state university in central US and found that the percentage of students waiting for A grade tends to increase notably over the years. Similarly, almost half of the students in 2017 graduated with honors from universities such as Princeton, University of South Carolina, and others ${ }^{11}$. In a comprehensive study of Rojstaczer and Healy (2012), it was found that grades gradually rose since the 1930s and 1940s. However, a sharp increase was detected in the 1960s, which was balanced in the 1970s. The sharp increase was often due to some instructors hesitating to give low grades at that time because the men with low scores were sent to the Vietnam War ${ }^{9}$. After the 1970s, according to Seldin's (1998) calculations, every decade, the average grades began to rise again between 0.10 to 0.15 (range of $0-4$ ). Grade inflation does not only apply to mediocre US universities. For example, at Harvard University, the percentage of A grades increased from $22 \%$ in 1966 to $46 \%$ in $1997^{14}$, which resulted in $91 \%$ of the 2001 graduates being awarded an honor degree ${ }^{15}$. Graduates of the elite "Ivy League" universities received higher grades than other universities in the US ${ }^{6,15-18}$ 
Many factors influenced the increase in grades in higher education. For example, Schutz et al. (2015). ${ }^{12}$ attributed this increase to three factors: (a) student evaluation of classes became mandatory, (b) students became increasingly career-oriented, and (c) learning outstripped family income. Rosovsky and Hartley (2002) stated the reasons for rising grades as higher incentives arising from the draft of the Vietnam War, response to student diversity, new curriculum or grading policies, responses to student assessments ${ }^{20-22}$, and growing culture of consumption. Some researchers reported that the need to improve the registration of certain undergraduate programs ${ }^{21,23-27}$ also triggered the elevation of grades. William, Li, and Wing (2007), Tampieri (2011), and De Witte, Geys, and Solondz (2014) added that competition between colleges also encourages grade inflation to put students in better jobs. Moreover, the additional resources provided to state institutions may also lead to note inflation. Hernández-Julián (2010) showed that grade-dependent scholarships can lead students to search for easier classes to maintain the required grade point average. Bar, Kadiyali, and Zussman (2009) examined a policy change that provides information on course notes, and this policy change encourages students to switch to higher grade courses. This indicates that changes increase grades. Again, many researchers have found that advanced social and economic appropriateness related to assessing students' scores is one of the main factors contributing to the phenomenon of grading inflation ${ }^{33-36}$. High grades given by instructors are grade inflation for some but does not apply to everyone. Kohn (2002) believes that higher grades may be the result of a good educator, better assignments, a more regular course schedule, and more communication with students concerning course requirements ${ }^{38}$. Winzer (2002) states that institutional changes, changes in student demography (e.g., student entitlement mentality, increase in the ratio of female students and adult students), uncertainty of faculty-student relationship, and curriculum changes cause an increase in gradings.

Note inflation affects not only the academy but also the labor market. Grading inflation causes cumulation at the top end of the grading distribution, which makes it difficult for the best students to stand out. Workplaces can rely on grades to help distinguish talented students, but due to note inflation and compression, they do not have sufficient clarity for hiring processes. This prevents a company's potential productivity and reduces students' incentives to work hard in the hope of being hired by the best companies ${ }^{40,41}$. It is also a process that reduces the reliability of higher education, which is one of the key institutions for inflation, meritocracy, and upward social mobility ${ }^{42,43}$. Although it is easy to assume that grade inflation is not a common sociological problem area of interest, it is only an educational research area. The theories of class inflation generally indicate a structural change in the broader society and social institution of higher education ${ }^{19}$, which, in turn, forms the micro-level incentive system. The influence of macro-level structural changes on micro-level social interactions was arguably the crux of sociological research of organizations ${ }^{44}$.

To sum up, grade inflation refers to a tendency to reduce academic requirements and give students higher grades than they deserve ${ }^{45}$. Additionally, grade inflation is a process followed by higher education institutions that reduces the actual value of A grade to an average grade value ${ }^{2}$. Grade inflation weakens standards, making it difficult to compare grades with knowledge and qualifications ${ }^{3}$. From this perspective, Crumbley, Flinn, and Reichelt (2012), described grade inflation in higher education institutions as a "fatal symbiosis". There is no consensus on the causes and consequences of grade inflation. Regardless of the reason, there are three issues related to the phenomenon of grade inflation in contemporary higher education. The first is related to the fact that the distribution of letter grades by time increases (inflation), and thus, A and B are given more than $\mathrm{C}, \mathrm{D}$, or $\mathrm{F}$. The second is the potential factors affecting the course grade. The third issue is more novel: Whether the COVID-19 pandemic will cause grading inflation in US universities during the Vietnam War? In other words, did the process of compulsory distance education trigger the inflation of grades? This study is analyzes these three issues.

\section{Hypotheses}

The aim of this study is to examine the change in the ratio of those graduated with a "very good (>2.99)" degree from pre-graduation medical training in Turkey, the grade inflation (increase), and factors that affect the course grade. This main objective forms the first hypothesis of the study which can be formulated as $\mathrm{H}_{1}$. The ratio of those graduated with a "very good (>2.99)" degree from the pre-graduation medical training in Turkey is increasing. The second hypothesis is $\mathrm{H}_{2}$ : There is grade inflation in the pre-graduation medical training in Turkey. Students' sex, the type of universities (public or non-profit private), accreditation of the program, age of the faculty, medium of education, and differences in university entrance points, which were assumed to affect grades, were disregarded to validate this hypothesis. Thus, absolute grade inflation was calculated. The last hypothesis is the $\mathrm{H}_{3}$ : The class size, the academic degree of the tutor, grade, content of the course, types of the universities (public \& non-profit private), accreditation of the program, and the age of the faculty have an impact on course grades. Therefore, the aim of the study is to investigate the following questions:

1. What is the ratio of those who graduated with a "very good $(>2.99)$ " degree from the pre-graduation medical training in Turkey?

2. Is there grade inflation in the pre-graduation medical training in Turkey?

3. Do class size, the academic degree of the tutor, grade, content of the course, types of the universities (public \& non-profit private), accreditation of the program, and the age of the faculty have an impact on the course?

\section{Methodology}

The data of this study included the pre-graduation medical training of medical faculties in 25 universities in Turkey. The criterion for determining universities is the university entrance percentile rankings. The schools were ranked based on their percentiles and divided into five groups considering the percentiles of the last students who entered the medical faculty programs of all medical faculties that had graduate students. Lastly, the study was carried out using the data (grades) obtained from 25 medical faculties, which are five of each entry-level. The data included the years between 2005 and 2020. The data included a 15year long period between the 2014-2015 academic year and 2019-2020 academic year. Two types of data were used in the study. Firstly, the GPA data of students who graduated within the abovementioned 15-year-long period were used to examine the grade inflation and the change in the ratio of those graduated with a "very good (>2.99)" degree. These data included 9.618 students' grades. Secondly, the grade data that were formed at the end of the academic year for each course were used to determine the factors that affect course[1] grades. These data included 288.540 students' grades for 7.597 
courses. The semantic (between AA-FF) letter system of the relevant faculty was converted to a 5-point scale to calculate the mean grade in each course, so the mean grade may change between 4.0 (a course where all students got AA) and 0 (a course where all students got FF).

Firstly, the sex of graduates, the percentile of the last student who entered the program, some university properties (the type of the university (public or nonprofit private), program accreditation, age of the faculty, medium of education) were included in the analyses regarding the grade inflation and the changes in the ratio of those graduated with a "very good (>2.99)" grade in this study. The "real" (university) random effects estimator (REE) developed by Greene (2005) was used to consider the differences in universities in terms of the year. This tool develops older stochastic random effects panel models to separate the changes of some properties of the university in time from the heterogeneity of the university profile ${ }^{47}$.

The literature given in the previous section reveals that grade inflation differs according to class population, academic history of the instructor, class level, fields, and university entry scores. Many factors can affect the average grade given in a particular course. In this study, eight potential bias factors were examined: classroom population, academic history of the instructor, class level, content (field), types of the universities (public \& non-profit private), English and Turkish medium education program, The accreditation of medical faculties and faculty age. Each factor was individually examined using correlation, ANOVA, and t-tests, and the factors associated with the average course grade are included in the final analysis (ANCOVA) as a common variable. Including these factors in the analysis as common variables, when testing the main relationship, meaning comparing the notes given before the setting, provides data to check the side effects that the main relationship may cause.

\section{Footnote:}

[1]Subject committees that consist of subjects related to each other in medical faculties where integrated medical education is provided were regarded as courses in this study.

\section{Results}

\section{Graduates with the "Very Good (>2.99)" Degree}

It was found that the ratio of graduates with the "very good ( $>2.99)$ " degree in Turkey was $17 \%$ in 2005 and it increased to $46 \%$ in 2020 . It was also found that the ratio of those graduated with a "good (2.50-2.99)" degree increased from $35 \%$ to $40 \%$ in this period whereas the ratio of those graduated with a "moderate (2.00-2.49)" degree decreased from $48 \%$ to $14 \%$ (Graph 1).

The change in the ratio of those who graduated with a "very good" degree was examined using the stochastic limit coefficient estimations of REE (Table 1). The results showed that the coefficient, which indicated that women are more likely to graduate with a "very good" degree compared to their male peers, is statistically significant. This result is proof that being a woman has a positive and significant effect on performance. Point estimation shows that a $1 \%$ increase in the ratio of women among the students increased the average of those graduated with a "very good" degree at the ratio of $0.09 \%$ (when all other factors are constant). A significant and positive correlation was found between the percentile of the last student who entered the medical faculty (high entrance score increases as the percentile decreases) and the ratio of those graduated with a "very good" degree. For example, a $10 \%$ increase in the entrance percentiles (entrance with a lower score) increases the ratio of those graduated with a "very good" degree at the ratio of $2.5 \%$ (when all other factors are constant). This also showed that a university that accepts students from the high percentile (with a low score) will graduate $4 \%$ more students with a "very good" degree compared to a university that accepts students from the low percentile (with a high score).

The results obtained in the context of university properties can be summarized as follows. The coefficient, which indicates that it is more likely for students in non-profit private universities to graduate with a "very good" degree than students in public universities, is statistically significant. The point estimation shows that a $1 \%$ increase in the students in non-profit private universities increased the average of those graduated with a "very good" degree at the ratio of $0.57 \%$ (when all other factors are constant). The coefficient, which indicates that it is more likely for students of a nonaccredited university to graduate with a "very good" degree than students in an accredited university, is statistically significant. The point estimation shows that a $1 \%$ increase in the students of a nonaccredited university increased the average of those graduated with a "very good" degree at the ratio of $0.27 \%$ (when all other factors are constant). The coefficient, which indicates that it is more likely for students in English medium education programs to graduate with a "very good" degree than students in Turkish medium education programs, is statistically significant. The point estimation shows that a $1 \%$ increase in the students in English medium education programs increased the average of those graduated with a "very good" degree at the ratio of $0.11 \%$ (when all other factors are constant). A significant and negative correlation was found between the ages of faculties and the ratio of those who graduated with a good degree. For example, the point estimation shows that a $10 \%$ increase in the age of the faculty decreases the average of those graduated with a "very good" degree at the ratio of $0.17 \%$ (when all other factors are constant). This also showed that young faculties will graduate $6 \%$ more students with a "very good" degree compared to relatively older faculties.

A continuous increase was observed in the estimated coefficients in year dummies. Additionally, estimated coefficients for year dummies are statistically significant as of 2009 after checking the features of students and universities ( $p<.001$ ). The point estimation of 200 dummy (when all other factors are constant) showed that the ratio of those graduated with a "very good" degree, which was $17 \%$ in the 2005 academic year, increased to $45 \%$ with a $25 \%$ increase (Graph 1); and this means that it explains almost all of the $29 \%$ increase in the ratio of those graduated with a "very good" degree before checking the variables. These results are proof that there is grade inflation in the pre-graduation medical training in Turkey within the last 15 years.

Table 1. Standard random effects estimates 


\begin{tabular}{|ll|}
\hline Variable name & Random Effects \\
\hline Students characteristics & $0.09(0.079)^{\star}$ \\
\hline In (\% Female) & $-0,25(0.041)^{*}$ \\
\hline In (percentile of the last student) & \\
\hline University characteristics & $0,57(0.189)^{*}$ \\
\hline Non-profit private universities & $-0,27(0.125)^{*}$ \\
\hline Accredited university & $0,11(0.098)^{*}$ \\
\hline English medium education programs & $-0,17(0.081)^{\star}$ \\
\hline Faculty Age & 0.071 \\
\hline$\sigma i$ & 0.063 \\
\hline бe & 0.619 \\
\hline rhoi & 0.432 \\
\hline Within- ${ }^{2}$ & 9.618 \\
\hline Observations & 25 \\
\hline Number of universities & \\
\hline
\end{tabular}

${ }^{*} p<0.001$

Note. Robust standard errors corrected for clustering by university are reported in parentheses. $\sigma i$ and $\sigma e$ are the estimated standard deviations for the fixed effects and the error term, respectively, $\rho i$ is the fraction of the variation in the dependent variable accounted for by the fixed effects and $\rho$ is the correlation between the fixed effects and the included variables.

\section{Grade Inflation}

While the students in the medical faculties in Turkey graduated with an average GPA of $2.41(S D=0.29)$ in 2005 , this average increased to 3.16 ( $S D=0.58)$ in the past 15 years (2020). This difference detected is quite high and statistically significant $(t=21.37 ; p<.001)$. Accordingly, a marginal increase of $31.12 \%$ in the graduation grades between 2005 and 2020 was detected, and this finding is an indicator of high-grade inflation in the pre-graduation medical training in Turkey. Considering the grade averages, there was an increase in every year compared to the previous year (except 2007). The highest-grade inflation on yearly basis was in the grades of students who graduated in 2020 with $4.64 \%$ followed by students who graduated in 2017 with $3.62 \%$ (Graph 2 ).

The results of the former analysis showed that the following six factors were associated with the graduation grade: sex, the percentile of the last student who entered the program, types of the universities (public or non-profit private), program accreditation, age of the faculty and medium of the education. The average values corrected according to these six factors were calculated with the ANCOVA for each year (Graph 2). A marginal increase of $29 \%$ was detected in the graduation grades in terms of the corrected averages, but there is high-grade inflation in the pre-graduation medical training in the past 15 years even when the factors that affect the grades are taken under control.

\section{Factors that Affect Course Grade}

\section{Class Size Differences}

The total number of students in the class is at the top of factors that affect grades. The instructors had a greater opportunity to get to know students in classes with fewer students and they tend to be more flexible when they have more information about students' efforts. Even having a closer relationship can make it less likely for the instructor to give a "bad" grade with the fear of upsetting the student ${ }^{48}$. Thus, the correlation coefficient of the relationship between class sizes and average grades was examined. The results showed a significant and negative correlation between average grade and class size ( $r=-.36$, $p<.001)$. Accordingly, the fewer students in the class, the higher their average grade is.

\section{Differences Regarding the Academic Degree of the Instructor[2]}

Another one of the potential factors that affect the course grade is the academic degree of the instructor. All of the lessons in medical education in Turkey are given by instructors with a doctoral degree (Ph.D. \& M.D.) And these instructors have a hierarchical structure among themselves as an assistant professor, associate professor, and professor. In the data set of the study, $71 \%$ of the lessons were given by instructors with the highest two degrees (associate professor and professor). According to the results of ANOVA, the average grade $(M=2.93, S D=0.98)$ in lessons given by instructors titled professors, the highest academic degree, was higher than the average grades in lessons given by associate professors $(M=2.87, S D=0.95)$ and assistant professors $(M=2.61$, , $S D=0.91)(F=47.29 ; p<.001)$. In conclusion, the academic degree of the instructor affected the course grade.

\section{Grade Differences}


A potential deviation factor is the grade. The number of students is quite high in the first or second-grade courses because of the students who repeat the class and the upper-grade students who were unable to continue their classes. According to ANOVA results, there is a significant difference between the grades and average course grades ( $F=59.78, p<.001)$. The senior year (6th Grade) classes have the highest average grade $(M=3.47, S D=0.54)$ followed by the fifth $(M=3.21, S D=0.66)$ and fourth $(M=3.01, S D=0.69)$ grades. The first grade $(M=2.13, S D=0.89)$ has the lowest average grades followed by the second $(M=2.41$, $S D=0.88)$ and third $(M=2.74, S D=0.91)$ grades. In conclusion, the grade affects the course grade.

\section{Content (Field) Differences}

It is known that both the competencies expected from the students and the lessons they take are more complex and difficult according to the fields of the courses. For example, the courses in fields like surgical medicine where courses like medical pathology are predominant, are relatively more difficult than courses in basic medical sciences and require students to make more efforts. In this regard, another factor that potentially affects the grades is the field of the course. The differentiation of average grades of the courses based on their fields (Basic Medicine, Internal Medicine and Surgical Medicine) was examined with the ANOVA. The results showed that there was a difference between average course grades in terms of the field of the course $(\mathrm{F}=39.27, p<.001)$. The lowest grades were given in basic medicine $(M=2.31, S D=0.93)$ while the highest grades were given in surgical medicine $(M=3.07, S D=0.59)$. The average grade in internal medicine was $2.87(S D=0.63)$. Accordingly, the field of the course affects the course grade.

\section{University Differences}

The universities in Turkey are divided into two as public and non-profit private universities. Education is free of charge in all programs of public universities (including the pre-graduation medical training). Education programs of private universities are paid. The education fee of the medical faculty in private universities changes between $58.000 \mathrm{TL}$ and $151.000 \mathrm{TL}(M=93.80, S S=23,93)$. However, it is mandatory for private universities to spare at least $15 \%$ of the total placement to beneficiary students for each program. Thus, another factor that potentially affects the grades is the type of university (public or private). In this regard, the differentiation of average course grades of the program based on the type of the university was examined with the t-test. The results showed that there was a difference between the grades given in public universities and grades given in private universities ( $\mathrm{t}=29.33, p<.001)$. The course grades in private universities $(M=3.11, S D=0.86)$ are quite higher than the course grades in public universities $(M=2.54, S D=0.82)$. In conclusion, the type of university affected the course grade.

\section{English medium education programs}

The accreditation of medical faculties in Turkey is made by the Association for Evaluation and Accreditation of Medical Education Programs. The association is a quality agency recognized by the Higher Education Quality Committee and World Federation for Medical Education and carries out national and international medical education accreditation operations. The accreditation process of medical faculties in Turkey started in 2011 , and the accredited education program is carried out in 41 of the existing 111 medical faculties (TEPDAD, 2020). Accreditation expresses the assessment and external quality assurance process that measures whether the pre-determined academic and field-specific standards are met by a higher education program. In this regard, it is an expected process for accredited higher education institutions to have a standard for both education and assessment-evaluation processes. Thus, another factor that potentially affects the grades is the accreditation of the program. In this regard, the differentiation of average course grades of the program based on whether the university is accredited was examined with the t-test. The results showed that there was a difference between the grades given in accredited programs and the grades given in non-accredited programs $(\mathrm{t}=21.93, p<.001)$. The course grades in non-accredited programs $(M=3.11, S D=0.86)$ are quite higher than the course grades in accredited programs $(M=2.76, S D=0.79)$. In conclusion, the accreditation of the program affected the course grades.

\section{Age Differences of Faculties}

The age of the faculty is closely related to various variables from the recruitment of lecturers and physical opportunities to the quality of various education programs. The ages of the faculties are at the top of factors that affect grades. The sufficiency of lecturers and physical opportunities are more limited in relatively young faculties; thus, expectations from students tend to be lower in such faculties. Thus, the correlation coefficient of the relationship between the ages of faculties and average course grades was examined. The results showed a significant and negative correlation between the age of the faculty and average grade $(r=-.62, p<.001)$. Accordingly, the younger the faculties are, the higher the average course/lesson grade is.

\section{Footnote:}

[2]This analysis was carried out though separate courses the outside of the structure of "committee" carried out by many faculty members.

\section{Discussion And Conclusions}

The aim of this study was to examine the neglected grade inflation in higher education literature. Moreover, the study examined the change in the ratio of those graduated with a "very good (>2.99)" degree within the past 15 years, grade inflation (when all other factors are constant) and the factors that affect course grade. Therefore, the study is authentic in terms of the other studies in the literature and provides some important proofs about the pre-graduation medical training in Turkey.

A common expression for increasing grades is "inflation" which means giving higher grades for equivalent work ${ }^{49}$. The results revealed that there was a marginal increase in grades in the medical training in Turkey even after the other factors that might affect the graduation grades were taken under control. A $31 \%$ grade inflation (from 2.41 to 3.16) detected within the past 15 years is the highest value that is reported in the literature. A series of studies documented the increase in average undergraduate grades in the last half-century. Average grades at US universities, where the most common analyses conducted on grade inflation, from 1960 to 2006, in approximately 50 years average grades rose from 2.5 to 3.1 (4 on a rating scale of points) ${ }^{49,50}$. Again, Rojstaczer and 
Healy $(2010 ; 2012)$ stated an increase of roughly 0.1 ( 0 to 4$)$ in every decade since the 1960 s. Specifically, it is found that from 1960 , the grades increased roughly 0.7 on average in private universities and 0.5 in public universities. Similarly, Summary and Weber (2012) found that the average grade of 2.6 (GPA) at a university in southeastern Missouri increased to 3.1 in 2004. Similarly, the grades rose from 2.83 to 2.97 between 1993 and $2004{ }^{51}$. While Carter and Lara (2016) stating a tendency to increase of grade distributions in US UC and CSU campuses between 2009 and 2013, they reported a significant increase in GPA in only half of the UC campuses during this time. Although the size of grade inflation varies according to data sources, evidence shows that when evaluated together, grades increase around 0.1 every decade.

Calculating grade-inflation only on grade calculations can cause errors. Some potential factors in the context of years lead to an increase in grade. Increased student diversity, new curriculum or grading policies, importance of student assessments, improved quality of education; and improvement in teaching skills of instructors can be examples for these factors ${ }^{7,29,52}$. And some of the researchers don't believe that there is grade inflation. Mostrom and Blumberg (2012) stated that the rise of grades does not necessarily mean inflation, and they argue that the situation they call as grade improvement may be. The instructors who describe the requirements of the course, the evaluation lists and the interest of students in the classroom are more likely to have students who will really learn and therefore receive higher grades. Again, Summary and Weber (2012) note change is not due to inflation, but due to productivity improvements, which naturally increases students' learning and understanding. But the analyzes conducted showed that after the effects of these factors were checked, the average increase in grades, that is, roughly half the unconditional increase ${ }^{49}$. The highest-grade inflation in the pre-graduation medical training in Turkey yearly was detected between 2020 and 2017. Additionally, there is a quite high-grade inflation increase as of 2017. A coup was attempted on 15 July 2016 in Turkey. 15 private universities under cover of the FETO terrorist group who attempted the coup, were closed on 23 July 2020 and the students were transferred to other universities. This result obtained in 2017 can be explained by the fact that these medical students, who completed the majority of their study in these universities, completed their senior year in public universities (according to analyses, the graduation grades are quite higher in private universities than public universities), and this reflected on their grades. Due to the Covid-19 pandemic which has taken the whole world under its impact in 2020, the courses and internships in the 2019-2020 academic year were completed in universities without the mandatory attendance as of March 2020 in Turkey. This finding of 2020 is in line with the finding reported in a comprehensive study (Author, 2020) that the pandemic period caused a $9.21 \%$ inflation in grades compared to previous years.

The results of this study reveal that the ratio of those who graduated with a "very good $(>2.99)$ " degree in the medical faculties in Turkey in 2020 increased compared to 2005. This study result is compatible with the literature. According to a recent study conducted by Hernández-Juliána and Looneyb (2016), 24\% of the grades in 1982 were $A, 35 \%$ were $B, 27 \%$ were $C, 9 \%$ were $D$ and $4 \%$ were $F$. The ratio of $A$ increased to $A$ in 2001 while the ratio of $D$ decreased to $6 \%$. The study also revealed that the factor that affects graduating with a "very good (>2.99)" degree the most is sex. This result is in line with many studies that advocate that being a woman causes a positive and significant effect on performance ${ }^{55-57}$. Women's participation in higher education is increasing for years in Turkey. Some studies ${ }^{47}$ in the literature determined that the increase in women's participation in higher education narrow downed the difference in performance based on sex and the fact that the ratio of women's participation in higher education in Turkey is increasing shows that there is no decrease in quality and ability.

Unlike previous studies 47,58 , a negative correlation was found between the university entrance scores and the percentage of graduating with a "very good" degree. There are many possible explanations for this. University placement processes are carried out centrally in Turkey. As a reflection of this situation, candidate students tend to make a selection based on previous rankings. One of the most important indicators that determine this ranking is the equivalent of the university and faculty in society. This situation may create pressure over faculty administrations and members of medical faculties, which have a tradition of very high entrance score, and this implicitly causes lower grade policies. Therefore, this result obtained in this study is an expected result for Turkey although it is not in compliance with the international literature.

The possibility of graduating with a "very good" degree is quite high both in private universities and young medical faculties. These results are in parallel with the literature. Unlike public universities which are funded fully by the public, university administrations may use grades as a tool to keep students in private universities, which are financed by the payments of students ${ }^{4}$. In fact, schools tend to make students and parents happy as they want to get high grades. One method to maintain students' happiness is to give them good grades ${ }^{38}$. Similarly, some studies revealed that the reputations of the universities that graduate their students with high degrees are not better than universities that graduate their students with low degrees ${ }^{59}$. Especially established universities are aware of grade inflation and take measures against this. For example, Princeton University declared that they will not allow more than $35 \%$ of grades to be $\mathrm{A}$ in all departments ${ }^{60}$.

Many countries use accreditation as a regulatory mechanism to improve medical education ${ }^{61}$. One of the most important results obtained is about the effect of accreditation on grade inflation. Both the course grades following the accreditation process and the inflation in the graduation grades (grade inflation) slowed down significantly in the accredited faculties. In this regard, it is an important example of the necessity of accreditation, which is referred to as the "golden standard" to improve the quality of medical education ${ }^{62}$. The result obtained is not surprising considering these explanations. Additionally, it can be stated that accreditation reflects the guarantee that the program manages the education and learning effectively leaving aside the accreditation debate in higher education. Therefore, medical faculty accreditation can serve as a tool to increase medical specialty and to encourage communication and interaction with society ${ }^{63}$.

The results of the study confirm some key findings in the literature. For example, both in the pandemic setting and before the pandemic, the academic background of the instructor, the class level, the fields and the university entrance scores are substantial determinants of the average course grades. Various studies have shown that student grades are related to the academic degree of the instructor. Research on this topic has demonstrated that low-grade faculty members consistently give far higher marks than high-grade faculty members ${ }^{64-67}$. But the findings obtained in the study are not compatible with the relevant literature. It was found that in Turkey the highest grades were given by the professors and the associate professors and the lowest grades were given by the

Page $7 / 11$ 
assistant professors. There are several possible explanations for this incompatibility. Entrance courses in Turkey are not preferred to be given by professors and associate professors compared to Anglo-Saxon countries, and these courses are mainly conducted by assistant professors. The findings of this study and results in the literature demonstrate that the lowest grades are given for the introductory courses. Because the number of students is relatively higher due to retakes and the difficulties that junior students face during adaptations. Another possible explanation comes from the cultural background of Turkish higher education. In Turkey, especially professors in faculties, do not devote much time to the assessments ${ }^{68}$. The given assessments are often carried out by their assistants. Another finding that should be interpreted along with this result is the lowest marks are given to courses given in the first year. It is also about Turkish culture to give low marks compared to other classes in first-grade courses. Instructors tend to punish students implicitly for potential problems that may occur in the future, based on the proverb "you will crush the head of the snake when small".

In conclusion, it is very clear whether the "grade inflation" observed in this study is a result of increasing efforts and handworks of students or more qualified student selection or "absolute" grade inflation. However, this study only reflects the pre-graduation medical training in Turkey. Additionally, the period of time used in this analysis covers 15 years, and a limited number of factors that are considered to affect grades were checked. These factors include a detailed description of the learning, teaching and evaluation strategies used in distance education courses, as well as a long period of identification of individual characteristics of the educators. The inclusion of these factors in the future empirical analysis will be productive for future research. In the future, it will also be interesting to study this situation in the context of various countries.

\section{Declarations}

Ethics approval and consent to participate: All procedures performed in studies involving human participants were in accordance with the ethical standards of the institutional and/or national research committee and with the 1964 Helsinki Declaration and its later amendments or comparable ethical standards.

Ethics Committee: Akdeniz University Ethics Committee for Education and Humanities

Date of the Board Meeting: 18.11.2020

Board Meeting Number: 21

Informed consent: It has been waived due to its true nature. Full name of ethics committee/IRB that waives the requirement for informed consent: Akdeniz University Ethics Committee for Education and Humanities

Consent for publication: Not applicable

Availability of data and materials: The datasets generated and analyzed during the current study are available from the corresponding author on reasonable request.

Competing interests: Author declare that they have no competing of interest.

Funding: No funding has been received for the study.

Authors' contributions: Full paper EK.

Acknowledgements: -

Datasets: The datasets used and analysed during the current study are available from the corresponding author on reasonable request.

\section{References}

1. Lee KB, Vaishnavi SN, Lau SKM, Andriole DA, Jeffe DB. “Making the grade:” Noncognitive predictors of medical students' clinical clerkship grades. J Nat/ Med Assoc. 2007;99(10):1138-1150.

2. Bar T, Kadiyali V, Zussman A. Putting grades in context. J Labor Econ. 2012;30(2):445-478. doi:10.1086/663591

3. Tucker J, Courts B. Grade inflation in the college classroom. Foresight. 2010;12(1):45-53. doi:10.1108/14636681011020155

4. Larry Crumbley D, Flinn R, Reichelt KJ. Unethical and Deadly Symbiosis in Higher Education. Account Educ. 2012;21(3):307-318. doi:10.1080/09639284.2012.667283

5. Pattison E, Grodsky E, Muller C. Is the Sky Falling? Grade Inflation and the Signaling Power of Grades. Educ Res. 2013;42(5):259-265. doi:10.3102/0013189X13481382

6. Astin AW. The changing American college student: Thirty-year trends, 1966-1996. Rev High Educ. 1998;21(2):115-135.

7. Rosovsky H, Hartley M. Evaluation and the academy: Are we doing the right thing. Cambridge, MA Am Acad Arts Sci. Published online 2002. Accessed December 14, 2020. www.amacad.org

8. Carter MJ, Lara PY. Grade inflation in higher education: Is the end in sight? Acad Quest. 2016;29(3):346-353. doi:10.1007/s12129-016-9569-5

9. Kuh GD, Hu S. Unraveling the complexity of the increase in college grades from the Mid-1980s to the Mid-1990s. Educ Eval Policy Anal. 1999;21(3):297320. doi:10.3102/01623737021003297

10. Eiszler CF. College students' evaluations of teaching and grade inflation. Res High Educ. 2002;43(4):483-501. doi:10.1023/A:1015579817194

11. Korn M. You graduated cum laude? So did everyone else. The Wall Street Journal. 2018. 
12. Rojstaczer S, Healy C. Where a is ordinary: The evolution of american college and university grading, 1940-2009. Teach Coll Rec. 2012;114(7). Accessed December 14, 2020. https://psycnet.apa.org/record/2012-22137-007

13. Seldin P. How colleges evaluate teaching: 1988 vs. 1998. AAHE Bull. 1998;50:3-7. Accessed December 14, 2020. https://scholar.google.com.tr/scholar? $\mathrm{hl}=\mathrm{tr} \& a s \_s d t=0 \% 2 C 5 \& \mathrm{q}=\mathrm{How}+$ colleges+evaluate+teaching\%3A+1988+vs.+1998\%3A+Practices+and+trends+in+the+evaluation+of +faculty+performance\&

14. Wilson BP. The phenomenon of grade inflation in higher education. Natl Forum. 1999;Fall:38-41. Accessed December 14, 2020. http://search.proquest.com/openview/e0b11350326ca3ce0362cb8709da0748/1?pq-origsite=gscholar\&cbl=25289

15. Haely P. Harvard Figures Show Most of Its Grades Are A's or B's - Google Akademik. The Boston Globe B.; 2001. Accessed December 14, 2020. https://scholar.google.com.tr/scholar?hl=tr\&as_sdt=0\%2C5\&q=Harvard+figures+show+most+of+its+grades+are+A\%27s+or+B $\% 27 s \& b t n G=$

16. Gose B. Efforts to curb grade inflation get an F from many critics. Chron High Educ. 1997;43(46). Accessed December 14, 2020. https://eric.ed.gov/? id=EJ549282

17. Kuh GD, Hu S. Unraveling the Complexity of the Increase in College Grades from the Mid-1980s to the Mid-1990s. Educ Eval Policy Anal. 1999;21(3):297320. doi:10.3102/01623737021003297

18. Popov S V., Bernhardt D. University competition, grading standards, and grade inflation. Econ Inq. 2013;51(3):1764-1778. doi:10.1111/j.14657295.2012.00491.x

19. Schutz KR, Drake BM, Lessner J, Hughes GF, Schutz Brent M Drake Janet Lessner Gail F Hughes KR. A Comparison of Community College Full-Time and Adjunct Faculties' Perceptions of Factors Associated With Grade Inflation. J Contin High Educ. 2015;63(3):180-192. doi:10.1080/07377363.2015.1085951

20. Anglin PM, Meng R. Evidence on grades and grade inflation at Ontario's Universities. Can Public Policy. 2000;26(3):361-368. doi:10.2307/3552406

21. Ewing AM. Estimating the impact of relative expected grade on student evaluations of teachers. Econ Educ Rev. 2012;31(1):141-154. doi:10.1016/j.econedurev.2011.10.002

22. Zangenehzadeh H. Grade inflation: A way out. J Econ Educ. 1988;19(3):217-226. doi:10.1080/00220485.1988.10845263

23. Achen AC, Courant PN. What are grades made of? In: Journal of Economic Perspectives. Vol 23. ; 2009:77-92. doi:10.1257/jep.23.3.77

24. Ehrenberg RG. Analyzing the factors that influence persistence rates in STEM field, majors: Introduction to the symposium. Econ Educ Rev. 2010;29(6):888-891. doi:10.1016/j.econedurev.2010.06.012

25. Jewell RT, Mcpherson MA. Instructor-specific grade inflation: Incentives, gender, and ethnicity. Soc Sci Q. 2012;93(1):95-109. doi:10.1111/j.15406237.2011.00827.x

26. Ost B. The role of peers and grades in determining major persistence in the sciences. Econ Educ Rev. 2010;29(6):923-934. doi:10.1016/j.econedurev.2010.06.011

27. Rask K. Attrition in STEM fields at a liberal arts college: The importance of grades and pre-collegiate preferences. Econ Educ Rev. 2010;29(6):892-900. doi:10.1016/j.econedurev.2010.06.013

28. William C, Li H, Wing S. A signaling theory of grade inflation. Int Econ Rev (Philadelphia). 2007;48(3):1065-1090. doi:10.1111/j.1468-2354.2007.00454.x

29. Tampieri A. Grade Inflation, Students'Social Background and String-Pulling.; 2011. Accessed December 14, 2020. https://core.ac.uk/download/pdf/6331317.pdf

30. De Witte K, Geys B, Solondz C. Public expenditures, educational outcomes and grade inflation: Theory and evidence from a policy intervention in the Netherlands. Econ Educ Rev. 2014;40:152-166. doi:10.1016/j.econedurev.2014.02.003

31. Hernández-Julián R. Merit-Based Scholarships and Student Effort. Educ Financ Policy. 2010;5(1):14-35. doi:10.1162/edfp.2009.5.1.5102

32. Bar T, Kadiyali V, Zussman A. Grade information and grade inflation: The cornell experiment. In: Journal of Economic Perspectives. Vol 23. ; $2009: 93-108$. doi:10.1257/jep.23.3.93

33. Isely P, Singh H. Do higher grades lead to favorable student evaluations? J Econ Educ. 2005;36(1):29-42. doi:10.3200/JECE.36.1.29-42

34. Nowell C. The Impact of Relative Grade Expectations on Student Evaluation of Teaching. Int Rev Econ Educ. 2007;6(2):42-56. doi:10.1016/S14773880(15)30104-3

35. Love DA, Kotchen MJ. Grades, course evaluations, and academic incentives. East Econ J. 2010;36(2):151-163. doi:10.1057/eej.2009.6

36. Todd Jewell R, McPherson MA, Tieslau MA. Whose fault is it? Assigning blame for grade inflation in higher education. Appl Econ. 2013;45(9):1185-1200. doi:10.1080/00036846.2011.621884

37. Kohn A. The dangerous myth of grade inflation. Chron High Educ. 2002;49(11):B7.

38. Schroeder N. Grade inflation: Faculty lived-experiences and perceptions. Published online 2016. Accessed December 14, 2020. http://search.proquest.com/openview/79a07ca6cc613a9520989706c1624ada/1?pq-origsite=gscholar\&cbl=18750\&diss=y

39. Winzer M. Grade inflation: An appraisal of the research. Univ Lethbridge. Published online 2002. Accessed December 14, 2020. https://scholar.google.com.tr/scholar?hl=tr\&as_sdt=0\%2C5\&q=\%29.+Grade+inflation\%3A+An+appraisal+of+the+research\&btnG=

40. Schwager R. Grade inflation, social background, and labour market matching. J Econ Behav Organ. 2012;82(1):56-66. doi:10.1016/j.jebo.2011.12.012

41. Nordin M, Heckley G, Gerdtham U. The impact of grade inflation on higher education enrolment and earnings. Econ Educ Rev. $2019 ; 73$. doi:10.1016/j.econedurev.2019.101936

42. Hunt L. Grade Inflation: Academic Standards in Higher Education. Suny Press; 2008. Accessed December 14, 2020. https://www.google.com/books? $\mathrm{hl}=\mathrm{tr} \& \mid \mathrm{r}=\& \mathrm{id}=$ =cuT_EnGHM9wC\&oi=fnd\&pg=PR7\&ots=e532SqX7_K\&sig=lfkcNdqpBmllCaS1 ofsRuoJztE0 
43. Todd Jewell R, McPherson MA, Tieslau MA. Whose fault is it? Assigning blame for grade inflation in higher education. App/ Econ. 2013;45(9):1185-1200. doi:10.1080/00036846.2011.621884

44. Huber J. Macro-Micro Linkages in Sociology. Sage; 1991.

45. Berezvai Z, Lukáts GD, Molontay R. Can professors buy better evaluation with lenient grading? The effect of grade inflation on student evaluation of teaching. Assess Eval High Educ. Published online 2020. doi:10.1080/02602938.2020.1821866

46. Greene W. Fixed and random effects in stochastic frontier models. In: Journal of Productivity Analysis. Vol 23. ; 2005:7-32. doi:10.1007/s11123-004-85451

47. Bachan R. Grade inflation in UK higher education. Stud High Educ. 2017;42(8):1580-1600. doi:10.1080/03075079.2015.1019450

48. Sonner BS. Adjunct": Examining Grade Inflation in Higher Education. J Educ Bus. 2000;76(1):5-8. doi:10.1080/08832320009599042

49. Hernández-Julián R, Looney A. Measuring inflation in grades: An application of price indexing to undergraduate grades. Econ Educ Rev. 2016;55:220-232. doi:10.1016/j.econedurev.2016.11.001

50. Rojstaczer S, Healy C. Grading in American colleges and universities. Teach Coll Rec. 2010;4(Figure 1):1-6.

51. Babcock P. Real costs of nominal grade inflation? New evidence from student course evaluations. Econ Inq. 2010;48(4):983-996. doi:10.1111/j.14657295.2009.00245.x

52. William C, Li H, Wing S. A signaling theory of grade inflation. Int Econ Rev (Philadelphia). 2007;48(3):1065-1090. doi:10.1111/j.1468-2354.2007.00454.x

53. Mostrom AM, Blumberg P. Does Learning-Centered Teaching Promote Grade Improvement? Innov High Educ. 2012;37(5):397-405. doi:10.1007/s10755012-9216-1

54. Summary R, Weber WL. Grade inflation or productivity growth? An analysis of changing grade distributions at a regional university. $J$ Product Anal. 2012;38(1):95-107. doi:10.1007/s11123-011-0259-6

55. Smith J, Naylor R. Determinants of degree performance in UK universities: A statistical analysis of the 1993 student cohort. Oxf Bull Econ Stat. 2001;63(1):29-60. doi:10.1111/1468-0084.00208

56. McNabb R, Pal S, Sloane P. Gender differences in student attainment: The case of university students in the UK. Published online 1998. Accessed December 14, 2020. http://www.opengrey.eu/item/display/10068/378864

57. Barrow M, Reilly B, Woodfield R. The determinants of undergraduate degree performance: How important is gender? Br Educ Res J. 2009;35(4):575-597. doi:10.1080/01411920802642322

58. Johnes G, Soo KT. Grades across Universities over Time. Manchester Sch. 2017;85(1):106-131. doi:10.1111/manc.12138

59. Moore DA, Swift SA, Sharek ZS, Gino F. Correspondence bias in performance evaluation: Why grade inflation works. Personal Soc Psychol Bull. 2010;36(6):843-852. doi:10.1177/0146167210371316

60. Damnjanovic LA. Princeton announces committee to review controversial grade deflation policy. Published 2013. Accessed December $14,2020$. http://dailyprincetonian.com/news/2013/10/princetonannounces-

61. Sethi A, Javaid A. Accreditation System and Standards for Medical Education in Pakistan: It's time we raise the bar. Pakistan J Med Sci. 2017;33(6). doi:10.12669/pjms.336.14178

62. Gordon D, Karle H. The state of medical and health care education: A review and commentary on the lancet commission report. World Med Heal Policy. 2012;4(1). doi:10.1515/1948-4682.1219

63. Leinster S. Role of accrediting bodies in providing education leadership in medical education. J Heal Spec. 2014;2(4):132. doi:10.4103/1658-600x.142779

64. Ford HT, Puckett JR, Tucker LA. Predictors of Grades Assigned by Graduate Teaching Assistants in Physical Education. Psychol Rep. 1987;60(3):735-739. doi:10.2466/pr0.1987.60.3.735

65. Jackson EJ. Acomparative study to determine the effectiveness of adjunct faculty in the business division at Fayetteville Technical Institute. Published online 1986. Accessed December 14, 2020. https://eric.ed.gov/?id=ED294622

66. Sonner BS, Sharland A. Grading Differences between Graduate Teaching Assistants and Faculty Members in the Introductory Marketing Class. J Mark Educ. 1993;15(2):44-49. doi:10.1177/027347539301500207

67. Williamson L, Pier J. Relationship between Instructor Degree Status and Student Grades in Basic Speech: A Research Report. Published online 1985. Accessed December 14, 2020. https://eric.ed.gov/?id=ED264632

68. Karadağ E, Yücel C. Distance Education at Universities during the Novel Coronavirus Pandemic: An Analysis of Undergraduate Students' Perceptions. Yuksekogretim Derg. 2020;10(2):181-192. doi:10.2399/yod.20.730688

\section{Figures}




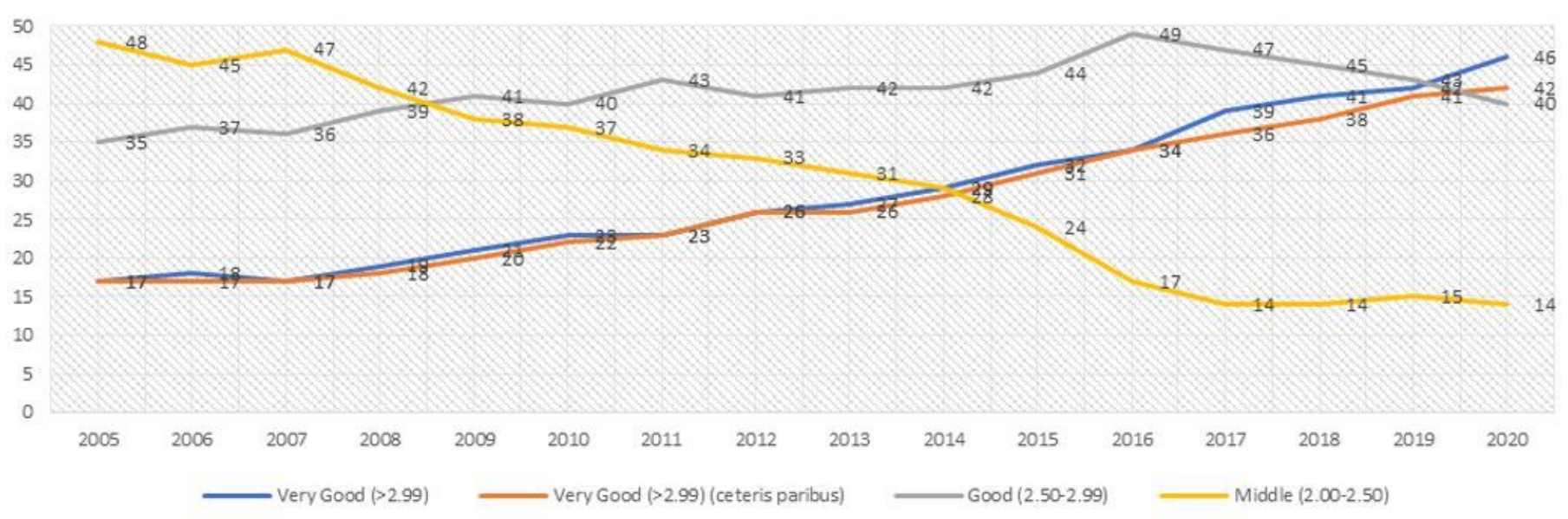

\section{Figure 1}

The graduation grade classification of all students

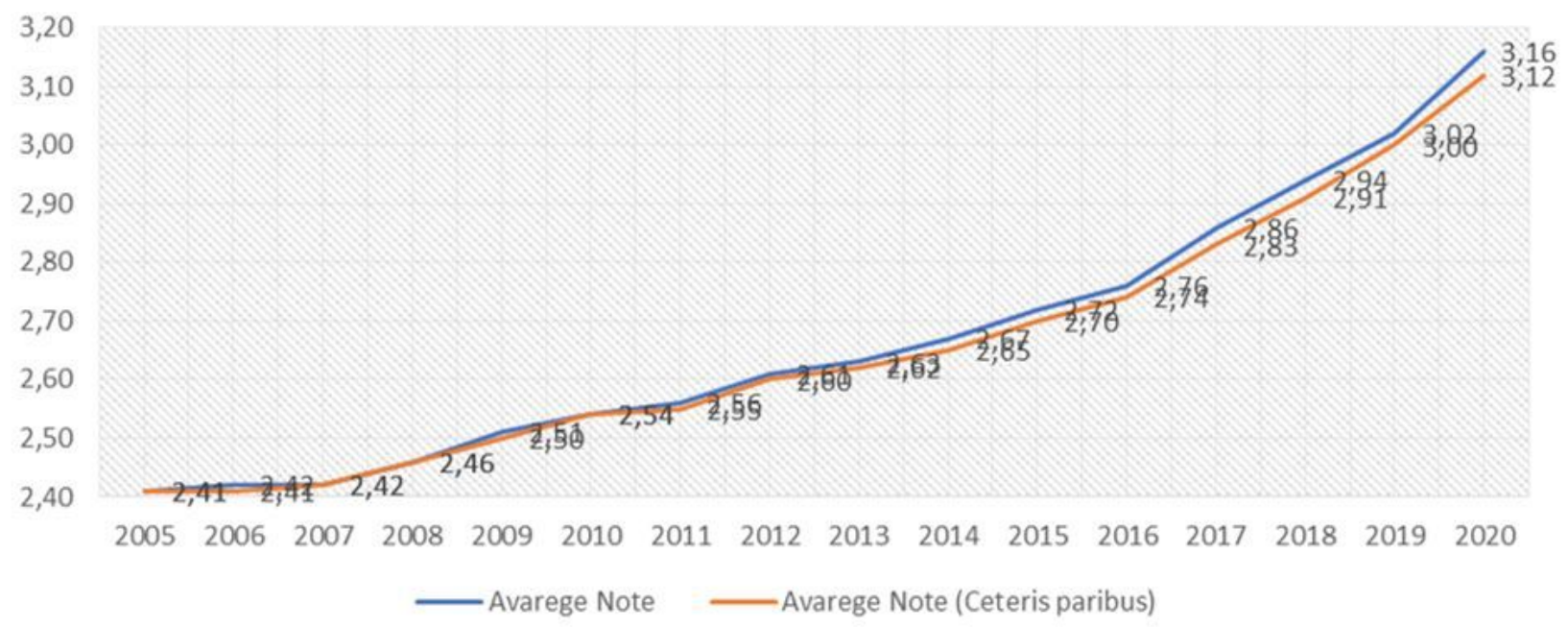

Figure 2

The graduation grades of all students 